\title{
SYSTEMS OF CARE FOR TRANSITIONAL AGE YOUTH (TAY) WITH \\ PSYCHIATRIC ILLNESSES THAT HAVE EXPERIENCED TRAUMA DURING \\ CHILDHOOD AND EARLY ADOLESCENCE
}

Timothy Van Deusen, MD ${ }^{1,2}$, Cynthia Wilson, MD ${ }^{1,3}$, Hyun Jung Kim, MD ${ }^{4,5}$

Hun Millard, MD ${ }^{1,3}$, Susan Parke, MD ${ }^{1,2}$, and Zheala Qayyum, MD ${ }^{4,6}$

${ }^{1}$ Yale School of Medicine Department of Psychiatry, New Haven, CT USA; ${ }^{2}$ Connecticut Mental Health Center, New

Haven, CT, USA; ${ }^{3}$ Yale New Haven Hospital, New Haven, CT USA; ${ }^{4}$ Harvard Medical School, Boston, MA, USA;

${ }^{5}$ McLean Hospital, Belmont, MA, USA; ${ }^{6}$ Boston Children's Hospital, Boston, MA, USA

\section{INTRODUCTION}

Trauma is a widespread, harmful and costly public health problem. It occurs as a result of violence, abuse, neglect, loss, disaster, war and other emotionally harmful experiences. Trauma has no boundaries with regard to age, gender, socioeconomic status, race, ethnicity, geography or sexual orientation. In particular, maltreatment in adolescence, regardless of type, appears to increase the chances of arrest, general and violent offending, and illicit drug use in young adulthood, even controlling for sociodemographic characteristics and prior levels of problem behavior. When children and adolescents have been traumatized, most are separated from their families and are placed in child welfare, foster or residential facilities. Studies have shown that the more placements a child experiences, the higher risk of attachment issues leading to a high risk of psychiatric morbidity in adulthood. In virtually every biopsychosocial domain, transitional youth at- risk from social disadvantage have worse outcomes than the general population of youth. Research has established that the impact of cumulative psychosocial risks, such as child maltreatment, exposure to other traumatic events (e.g. community and/or domestic violence), family disruption. These youth have varying degrees of life skills to become successful, and don't always have resources and/or programs addressing the needs of this vulnerable population. Research has shown that those who leave foster care without being linked to forever families have a higher likelihood than youth in the general population to experience homelessness, unemployment and incarceration as adults. About $33-45 \%$ of the "aged out" emancipated youth have been given at least one or more psychiatric disorders and will need help accessing adult mental health services in the community. They experience higher rates of mental health problems than the general population (e.g. PTSD is $5 \mathrm{X}$ rate and $28 \%$ recover vs $47 \%$ general population) $33-45 \%$ have been diagnosed with one or more psychiatric disorders while in foster care and prescribed psychotropic medications at 2-8X more than non foster youth. Also only about $10-15 \%$ of foster youth enter college and they tend to choose colleges with lower admissions criteria. Only $3 \%$ of foster youth will earn a Bachelor's degree from a 4 year college..

\section{OBJECTIVES}

When mental health and behavioral issues begin in childhood as a result of trauma, the children are usually evaluated and treated in publicly funded community child and adolescent clinics with clinical staff trained to work specifically with that age group. However, when these youth reach the age of $18-21$, child and adolescent services are terminated and those that suffer from persistent mental illness will terminated and those that suffer from persisten
need to seek treatment in adult care clinics.

\section{METHODS}

\section{Biological Effects:}

Abuse and Neglect have a direct effect on brain development. Preclinica data suggest that early life stress has detrimental effects on the brain's dopaminergic system, particularly the mesocorticolimbic pathway.

Altered dopamine function is thought to contribute to the development of stress-related pathologies.

But little is known about the impact of early stress on dopamine systems during childhood and adolescence, when stress-related disorders

frequently emerge.

\section{Psychological Effects:}

Multiple out of home placements prevents healthy attachments with caregivers and peers, and changing schools leads to poor educational

Feelings about reconnecting with family of origin

$64 \%$ report feeling close to birthmothers

If living with relatives, $95 \%$ report feeling close to them

Internal conflicts about reconnecting vs past treatment as children Difficulty forming new adult relationships based on numerous moves to new homes

\section{Social Effects:}

ack social supports which contribute to negative outcomes on physical and mental health

Multiple moves interfere with establishing stable and long term relationships

Disrupted education: missing school due to switching homes, most won't graduate high school at age 18

Disruptive social networks increase emotional distress

More than 20\% report homeless 1 day or more in last year

Review of research 1990-2011 shows between 11\%-36\% of 18-25 year

olds reports being homeless, compared to $4 \%$ general population

Risk factors include being male, ran away while in foster care,

delinquency, placement instability, history of physical abuse, mental

health issues

I HAVE NO DISCLOSURES

Yale SCHOOL OF MEDICINE
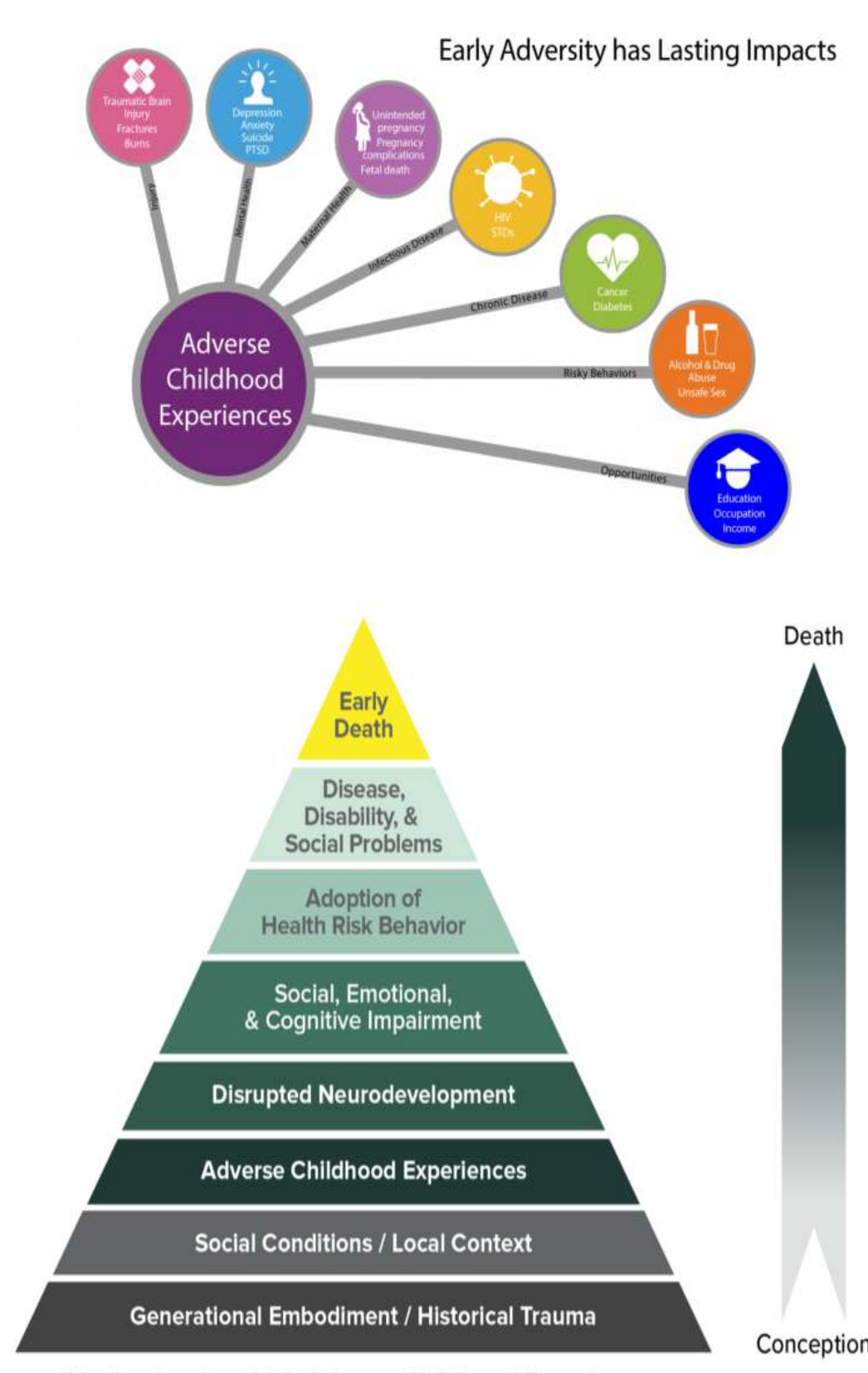

Mechanism by which Adverse Childhood Experiences
nfluence Health and Well-being Throughout the Lifespan

\section{LGBTQ+ Youth:}

Approximately $33 \%$ of LGBTQ+ students drop out of high school, nearly three times the national average leading to low graduation rates,

$40 \%$ of homeless youth (9-10\% of general population)

More likely to experience verbal and physical abuse while in care by peers and staf

4 times more likely to attempt suicide.

Intergenerational Trauma Effects (ITE)

ITE in the offspring of survivors of abuse, armed conflict, and genocide has been well documented

Offspring of parents who have experienced trauma are thought to themselves experience higher levels of childhood trauma Offspring of parents with PTSD have been found to have lower evels of urinary cortisol levels even if they themselves did not have PTSD

In animal models, fluctuations in maternal care of their infants results in longstanding changes in hippocampal glucocorticoid receptor expression and hypothalamic pituitary adrenal function that are then transmitted intergenerationally

More research regarding protective factors and resiliency to decrease ITE is needed.

\section{Trauma Informed Care (TIC)}

(TIC. SAMHSA's definition focuses on four key principles for programs, organizations, or systems to consider:

Realize the widespread prevalence of trauma

Recognize the signs and symptoms of trauma in clients, families, and staff. Respond by integrating knowledge into policies, procedures, and practices, Actively resist retraumatization of clients, families, staff, and others.

\section{Positive Transition Outcomes:}

- Resiliency and Strengths Orientations

Federally Legislated Supports

Transition Readiness Assessment

Mentoring

Financial Literacy

Postsecondary Education Support

Independent Living Programs

Mental Health Services for Transitional Age Youth

\section{Mentorship}

Mentoring relationships can be life changing.

Whether it is through structured programs or through relationships that develop on their own, mentoring has been shown to benefit youth.

Benefits may occur through a variety of mediating processes, such as changes in social and emotional development, cognitive development, identity development and all of the above

\section{Mental Health Programs:}

Few and far between, some hospitals and clinics are recognizing the need for transitional age youth services. Yale New Haven Hospital in New Haven, Connecticut, is one of the few hospitals in the USA with an inpatient unit and intensive outpatient program for patients age 18-25. Also, the state of Connecticut's Department of Mental Health and Addictions Services supports a Young Adult Service for 18-25 year old youth with psychiatric disorders located in several publicly funded licensed mental health clinics. These "wraparound" services provides outpatient psychiatric services, vocational and educational counseling, housing, occupational skills building and job internships, working with juvenile diversion, and the Substance Abuse Treatment Unit (SATU). These programs focus on the developmental needs of patients which improves compliance and adherence to treatment.

\section{RESULTS}

Participants will gain a greater understanding of the difficulties that youth with trauma histories and psychiatric disorders face when becoming young adults, and will learn how to minimize the risks of negative transitions while promoting positive transitions. Audience members will also learn that a trauma informed, developmental approach helps these youth attain their goal as a successful, well adjusted adult.

\section{CONCLUSIONS}

Child and Adolescent Psychiatrists can offer their knowledge and expertise in the developmental aspects of trauma during childhood, dolescence and young adulthood to inform policy, initiate research, provide support and treatment, and develop social plans and clinical programs for these youths.

\section{REFERENCES AND RESOURCES}

Singalong CC, Vang C. Intergenerational Trauma in Refugee Families: A Systematic Review. J Immigr Minor Health. 2017;19(3): 745-754. doi:10.1007/s10903-016-0499-7

Yehuda R, Halligan SL, Grossman R. Childhood trauma and risk for PTSD: relationship to intergenerational effects of trauma, parental PTSD, and cortisol excretion. Development and psychopathology. 2001;13:733-753. doi: 10.1017/\$0954579401003170

Yehuda R, Bierer LM. Transgenerational transmission of cortisol and PTSD risk. Prog Brain Res. 2008; 167: 121-135. doi: 10.1016/S0079-6123(07)67009-5

Lee, T., Morgan, W. Transitioning to Adulthood from Foster Care, Child Adolesc Psychiatric Clin N Am, 2017, 283-296.

SAMSHA's Concept of Trauma and Guidance for a Trauma-Informed July 2014, www.samhsa.org

Munson, M., McMillen, J., Natural mentoring and psychosocial outcomes among older youth transitioning from foster care, Children and Youth Services Review, 2009, 104-111

ransitioning Youth into Adult Mental Health and Addiction Services: An Outcomes Evaluation of the Youth Transition Project, The Journal of Behavioral Health Services \& Research, 2016,43.4 Southerland, D., Casanueva, C., Ringeisen, H. Young adult outcomes and mental health problems among transition age youth investigated for maltreatment during adolescence, Children and Youth Servic Review, 2009, 947-959 doi:10.1016/j.childyouth.2009.03.010 Stott, T. Transitioning Youth: Policies and outcomes. Children and Youth Services Review, 2013, 35, 218-227

Zelachoski, A. et.al. Traumatized youth in residential treatment settings: Prevalence, Clinical Presentation, Treatment, and Policy implications. Journal of Family Violence, 2013. DOI 10.1007/s10896-013-9534-9

Ahrens, K. et al. Association between childhood sexual abuse and transactional sex in youth aging out of foster care. Child Abuse and Neglect, 2012, 36, 75-80, doi:10.1016/j.chiabu.2011.07.009

Cusick, G., Havelicek, J., Courtney, M. Risk for arrest: The role of social bonds in protecting foster youth making the transition to adulthood, American Journal of Orthopsychiatry, 2012, 82:1, 19-31

The National Child Traumatic Stress Network, Creating traumainformed systems, 2016, nctsn.org

Capelli, M. et al, Transitioning Youth into Adult Mental Health and Addiction Services, Journal of Behavioral Health Services \& Research, 2014. 597-610.

Greeson, J. et al, It's good to know that you got somebody that's not oing anywhere: Attitudes and beliefs of older youth in foster care about child welfare-based natural $m$

Services Review, 2015, 48, 140-149

Graham, K. Schellinger, A, Vaughn, L. Developing strategies for positive change: Transitioning foster youth to adulthood. Children and Youth Services Review, 2015, 54, 71-79

Christian, C. et al, Child Maltreatment and the Transition to AdultBased Medical and Mental Health Care, Pediatrics, 2011, 127,1, 139-145

Contact info: timothy.vandeusen@yale.edu 